\title{
Comparison of Usual and Alternative Methods to Measure Height in Mechanically Ventilated Patients: Potential Impact on Protective Ventilation
}

\author{
Azadeh Bojmehrani Eng MSc, Maude Bergeron-Duchesne, Carmelle Bouchard Inh, \\ Serge Simard MSc, Pierre-Alexandre Bouchard Inh, Abel Vanderschuren MD, \\ Erwan L'Her MD PhD, and François Lellouche MD PhD
}

\begin{abstract}
BACKGROUND: Protective ventilation implementation requires the calculation of predicted body weight (PBW), determined by a formula based on gender and height. Consequently, height inaccuracy may be a limiting factor to correctly set tidal volumes. The objective of this study was to evaluate the accuracy of different methods in measuring heights in mechanically ventilated patients. METHODS: Before cardiac surgery, actual height was measured with a height gauge while subjects were standing upright (reference method); the height was also estimated by alternative methods based on lower leg and forearm measurements. After cardiac surgery, upon ICU admission, a subject's height was visually estimated by a clinician and then measured with a tape measure while the subject was supine and undergoing mechanical ventilation. RESULTS: One hundred subjects (75 men, 25 women) were prospectively included. Mean $P B W$ was $61.0 \pm 9.7 \mathrm{~kg}$, and mean actual weight was $30.3 \%$ higher. In comparison with the reference method, estimating the height visually and using the tape measure were less accurate than both lower leg and forearm measurements. Errors above $10 \%$ in calculating the PBW were present in 25 and 40 subjects when the tape measure or visual estimation of height was used in the formula, respectively. With lower leg and forearm measurements, 15 subjects had errors above $10 \%(P<.001)$. CONCLUSIONS: Our results demonstrate that significant variability exists between the different methods used to measure height in bedridden patients on mechanical ventilation. Alternative methods based on lower leg and forearm measurements are potentially interesting solutions to facilitate the accurate application of protective ventilation. Key words: protective mechanical ventilation; tidal volume; predicted body weight; height; ventilator-induced lung injury; acute lung injury; measure. [Respir Care 2014;59(7):1025-1033. (C) 2014 Daedalus Enterprises]
\end{abstract}

\section{Introduction}

In patients with ARDS, ventilation with high tidal volumes $\left(\mathrm{V}_{\mathrm{T}}\right)$ increases mortality, and protective ventilation

The authors are affiliated with the Centre de Recherche, l'Institut Universitaire de Cardiologie et de Pneumologie de Québec, Québec, Canada.

Supplementary material related to this paper is available at http://www.rcjournal.com.

The authors have disclosed no conflicts of interest.

Correspondence: François Lellouche MD PhD, Unité de Soins Intensifs de Chirurgie Cardiaque, Groupe de Recherche en Santé Respiratoire, with lower $\mathrm{V}_{\mathrm{T}}$ is now widely recommended. ${ }^{1-4}$ Several studies suggest that prophylactic protective ventilation should be

See the Related Editorial on Page 1155 used in most mechanically ventilated critically ill patients to avoid acquired $\mathrm{ARDS}^{5-7}$ and to improve outcome. ${ }^{6,8}$

Centre de Recherche, l'Institut Universitaire de Cardiologie et de Pneumologie de Québec, 2725 Chemin Sainte-Foy, Ville de Québec, Québec G1V 4G5, Canada. E-mail: francois.lellouche@criucpq.ulaval.ca.

DOI: $10.4187 /$ respcare. 02732 
It is well established that a patient's lung volume is well correlated to height, ${ }^{9}$ and this important physiologic value cannot be overlooked in mechanically ventilated patients. Indeed, protective ventilation implementation requires the calculation of predicted body weight (PBW) based on gender and height. ${ }^{1}$ Consequently, height inaccuracy may be a limiting factor to adequately reduce the $\mathrm{V}_{\mathrm{T}}$. In this regard, it should be emphasized that PBW rather than actual body weight must be used to calculate the prescribed $\mathrm{V}_{\mathrm{T}}{ }^{8,10}$ The use of actual body weight can lead to large errors in $\mathrm{V}_{\mathrm{T}}$ settings, ${ }^{11}$ especially in women and obese patients. ${ }^{8}{ }^{12} \mathrm{Vi}$ sual estimation of the patient's height is frequently used in mechanically ventilated patients. ${ }^{13,14}$ However, visual estimation of height and, even more so, of PBW can be inaccurate. ${ }^{15-18}$ In addition, despite strong evidence and recommendations, protective mechanical ventilation is not optimally implemented ${ }^{19-23}$; unavailability of the height may be an additional barrier. ${ }^{11}$

Considering the central role of the physiologic value of the patient's height and its impact on mechanical ventilation settings, we conducted this study to evaluate the accuracy of usual measurements of height in mechanically ventilated patients and to assess alternative measurements.

\section{Methods}

From July 2010 to December 2011, we conducted a prospective study to evaluate height measurement accuracy in patients requiring cardiac surgery at the Institut Universitaire de Cardiologie et de Pneumologie de Québec. Study approval was obtained from the local ethics committee, and informed consent was obtained from all subjects before surgery.

\section{Subjects}

The research coordinator screened patients before the surgery. The exclusion criteria were the inability of the patient to stand up for initial measurement, including emergent surgeries, and patients already on mechanical ventilation before surgery.

\section{Study Measurements}

Preoperatively. The reference method used for comparisons was the subject's actual height, measured with a height gauge while the subject was standing up. We also measured the lower leg length to calculate the height using the Chumlea method. ${ }^{24-26}$ We measured the lower leg length with a special caliper while the subject was sitting with knees bent at a $90^{\circ}$ angle. The length from the top of the knee (patella) to the bottom of the heel was measured. The subject's height was calculated using previously described equations. ${ }^{26}$ In addition, we measured the subject's fore-

\section{QUICK LOOK}

\section{Current knowledge}

Implementation of a lung-protective ventilation strategy requires the calculation of predicted body weight, determined from a formula based on gender and height. Any error in the measurement of height can lead to inappropriately set tidal volumes and failure to provide lung protection.

\section{What this paper contributes to our knowledge}

A significant variability exists between the different methods of measuring height in bedridden mechanically ventilated patients. Alternative methods of determining height based on lower leg and forearm measurements are potential solutions to facilitate the accurate application of protective ventilation.

arm with a tape measure between the olecranon process of the elbow and the midpoint of the prominent styloid process of the radius. We then calculated the height based on a previously described chart. ${ }^{27}$ Each measurement was performed only once for each subject, and two different investigators were involved in these measurements (Fig. 1).

Postoperatively. Within the first minutes after arriving at the ICU, other data were recorded while subjects were on mechanical ventilation. First, each subject's height was visually estimated by a nurse or a respiratory therapist and then subsequently measured by a nurse with a tape measure while the subject was supine in bed. Nurses and respiratory therapists were not aware of the subject's preoperative height (see Fig. 1). The PBW was calculated using the previously validated equations. ${ }^{1}$

\section{Statistical Analysis}

Data are presented as means \pm SD. Categorical variables are presented as counts. Agreement between results was expressed by the Bland-Altman method, ${ }^{28}$ and all data are presented using Bland-Altman plots. Estimated bias (average of the differences between the reference height [gauge] and the different measuring methods) and 95\% CI (bias $\pm 1.96 \times \mathrm{SD}$ ) were calculated. For errors of measurement, we calculated the mean of absolute difference between the reference and the different measuring methods. A generalized linear mixed model was performed using the normality or the binary model according to the data distribution. A compound symmetric structure was used to consider the dependence among measurements. Posteriori comparisons were performed using the Tukey technique. 


\section{Accepted standard}

Reference method for comparisons

\section{BEFORE SURGERY}

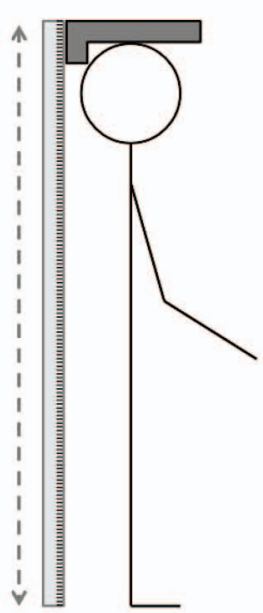

(1)

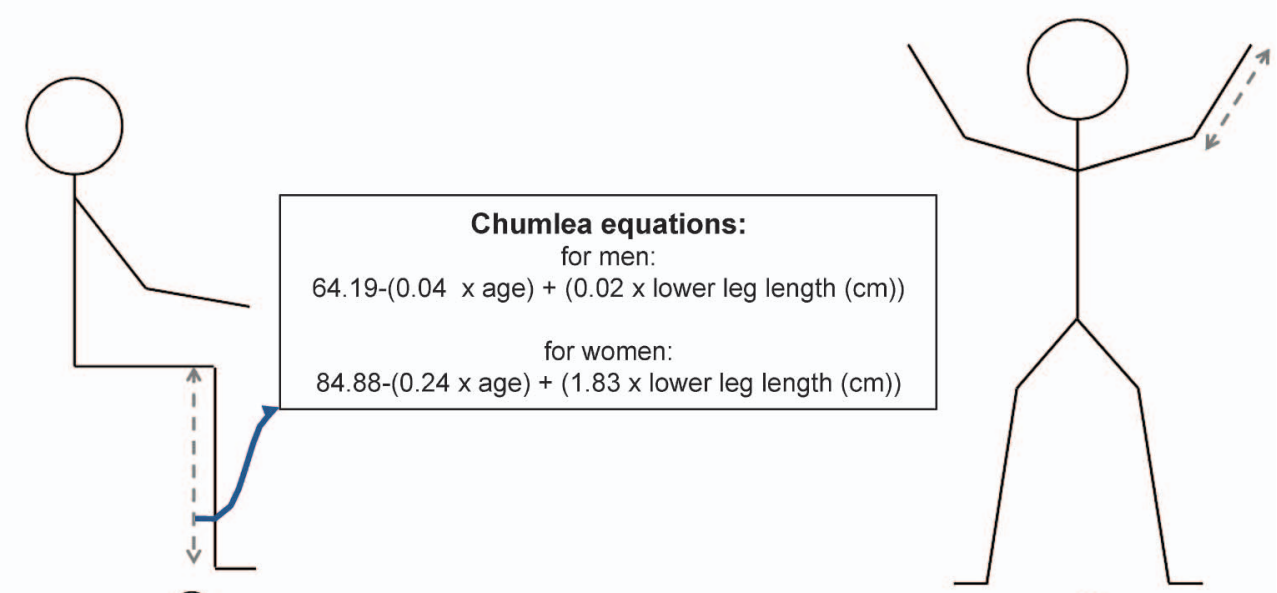

(2)

(3)

\section{AFTER SURGERY}

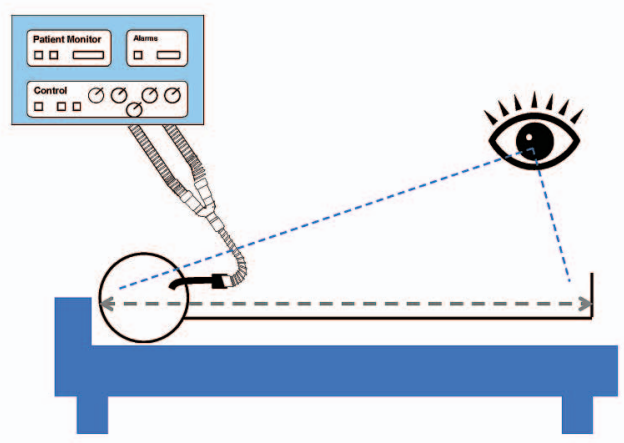

(4)

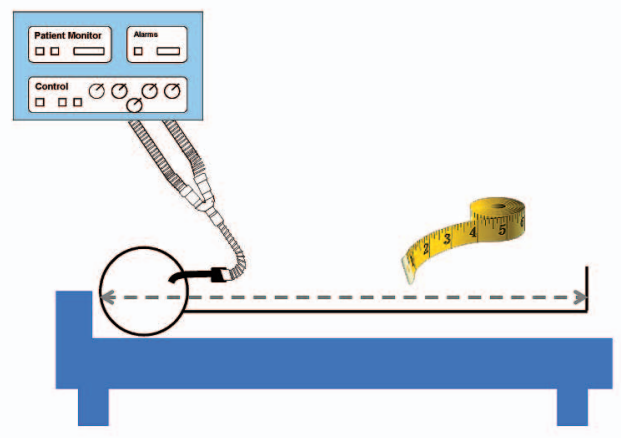

(5)

Fig. 1. Different methods to measure height. Five methods to obtain patient heights were compared. Preoperatively, subjects were measured with a height gauge while standing upright (1); this measure was used as the reference method. Lower legs (2) and forearms (3) were also measured, and subject height was derived from previously validated formulas. ${ }^{26,27}$ Formulas to predict height based on lower leg measurement are provided, based on Reference 26. Postoperatively, heights were visually estimated (4) by one clinician, and (5) subjects (bedridden in a supine position) were subsequently measured with a tape measure.

Relationships between the reference and the other methods of measurement were analyzed using Pearson correlation coefficients. All reported $P$ values were declared significant at .05. Data were analyzed using a statistical package (SAS 9.3, SAS Institute, Cary, North Carolina).

\section{Results}

\section{Subjects}

One hundred subjects (75 men, 25 women) with a mean age of $66.0 \pm 9.3 \mathrm{y}$ were studied. A total of 500 measurements of subjects' heights were obtained (5 measurements per subject). The mean actual weight was $79.5 \pm 17.6 \mathrm{~kg}$; the mean PBW was $61.0 \pm 9.7 \mathrm{~kg}$. The median (interquartile) height measured by height gauge before surgery was $167 \mathrm{~cm}$ (159-174 cm). Data on height obtained with the different measuring methods and errors in comparison with the reference measure are shown in Table 1.

\section{Differences Between Actual Height, Tape Measure Method, and Visual Estimation}

The results obtained using a tape measure and visual estimation were well correlated with the reference (height gauge) (Fig. 2). Compared with the reference, bias with the tape measure was $-3.7 \pm 5.0 \mathrm{~cm}(95 \% \mathrm{CI}-13.5$ to 6.2$)$, and bias with visual estimation was $-4.0 \pm 7.0 \mathrm{~cm}(95 \% \mathrm{CI}-17.7$ 


\section{Measuring Height and Protective Ventilation}

Table 1. Difference Between Reference Values and Other Methods for Height Measurement

\begin{tabular}{|c|c|c|c|c|c|c|}
\hline & $\begin{array}{l}\text { Height Gauge } \\
\text { (Reference) }\end{array}$ & $\begin{array}{c}\text { Visual } \\
\text { Estimation }\end{array}$ & $\begin{array}{c}\text { Tape } \\
\text { Measure }\end{array}$ & $\begin{array}{l}\text { Lower Leg } \\
\text { Measurement } \\
\text { (Chumlea) }\end{array}$ & $\begin{array}{c}\text { Forearm } \\
\text { Measurement }\end{array}$ & $P^{*}$ \\
\hline Height, mean $\pm \mathrm{SD}, \mathrm{cm}$ & $165.8 \pm 9.1$ & $169.6 \pm 8.3$ & $169.4 \pm 9.7$ & $168.2 \pm 9.0$ & $167.2 \pm 7.4$ & $<.001$ \\
\hline Bias, cm $(95 \% \mathrm{CI})$ & & $-4.0(-17.7$ to 9.7$)$ & $-3.7(-13.5$ to 6.2$)$ & $-2.4(-10.0$ to 5.2$)$ & $-1.3(-10.8$ to 8.6$)$ & \\
\hline Error, mean $\pm \mathrm{SD}, \mathrm{cm}^{\dagger}$ & & $6.4 \pm 4.8$ & $4.7 \pm 4.0$ & $3.7 \pm 2.6$ & $3.7 \pm 3.4$ & $<.001$ \\
\hline Maximum error, $\mathrm{cm} \dagger$ & & 20.5 & 19.0 & 11.9 & 20 & \\
\hline Error, mean $\pm \mathrm{SD}, \% \dagger$ & & $3.9 \pm 3.1$ & $2.9 \pm 2.5$ & $2.3 \pm 1.6$ & $2.3 \pm 2.0$ & $<.001$ \\
\hline Subjects with error $>5 \%, n \dagger$ & & 31 & 16 & 7 & 12 & .002 \\
\hline Subjects with error $>10 \%, n \dagger$ & & 5 & 2 & 0 & 1 & .074 \\
\hline Subjects with error $>20 \%, n^{\dagger}$ & & 0 & 0 & 0 & 0 & $>.99$ \\
\hline
\end{tabular}

* The statistical method is the generalized linear model with repetitive measurements

$\dagger$ Errors of measurement are comparisons with the reference value of height (measurement with height gauge before surgery while the subject was standing upright)

A

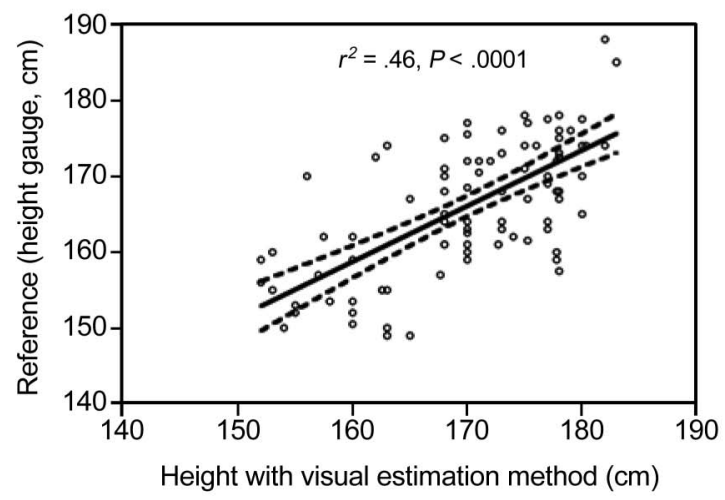

B

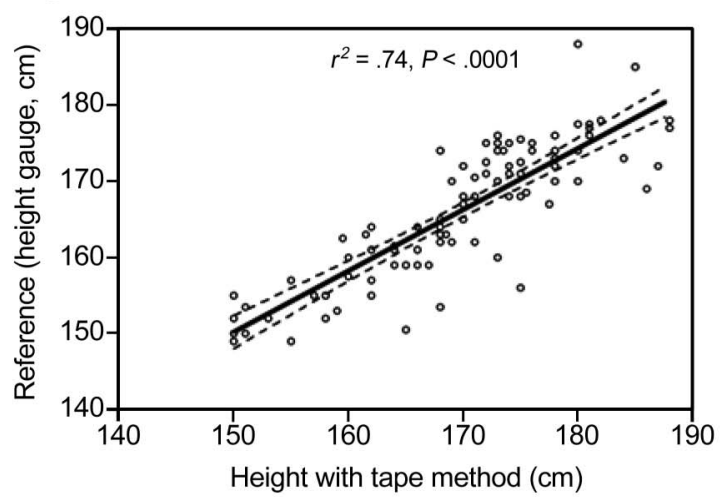

C

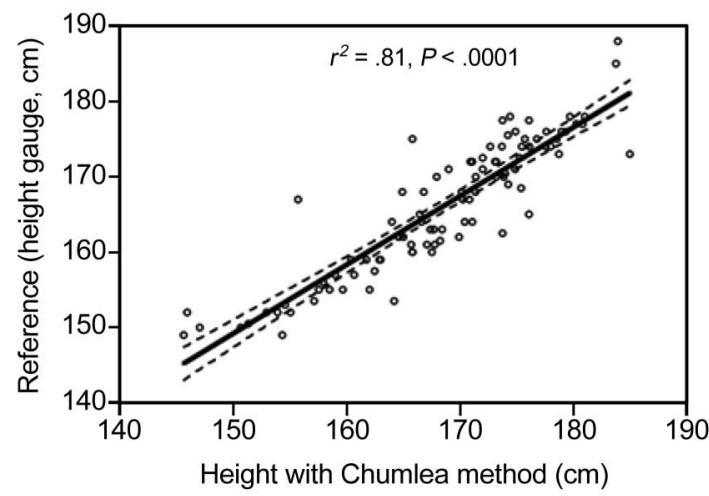

$\mathrm{D}$

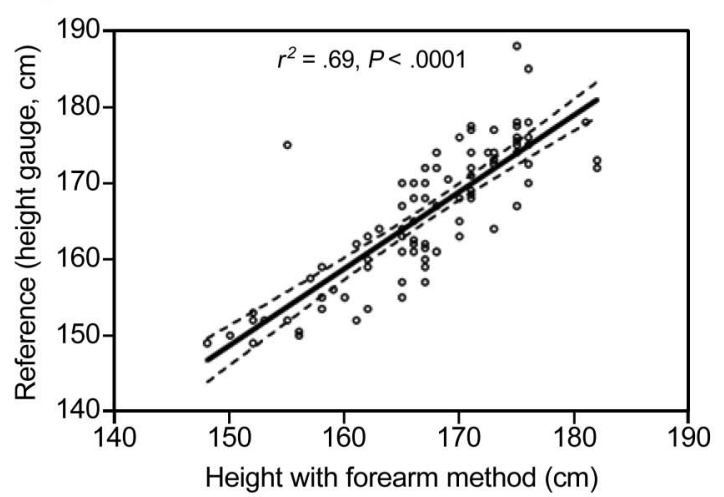

Fig. 2. Scatter plots with Pearson correlations between the reference values for height measurement and visual estimation (A), tape measure method (B), lower leg measurement (C), and forearm measurement (D). Solid lines represents the regression line, and dashed lines represent $95 \% \mathrm{Cl}$.

to 9.7) (Fig. 3). Maximum errors with tape measure and visual estimation were 19.0 and $20.5 \mathrm{~cm}$, respectively.

Error of visual estimation was inversely correlated to the subject's height $(\mathrm{r}=0.52, P<.001)$. (See the sup- plementary materials at http://www.rcjournal.com.) Mean error of visual estimation was significantly greater with shorter subjects (those with a median height of $\leq 167 \mathrm{~cm}$ : $7.3 \pm 6.7$ vs $0.4 \pm 5.5 \mathrm{~cm}, P<.001)$. 
A

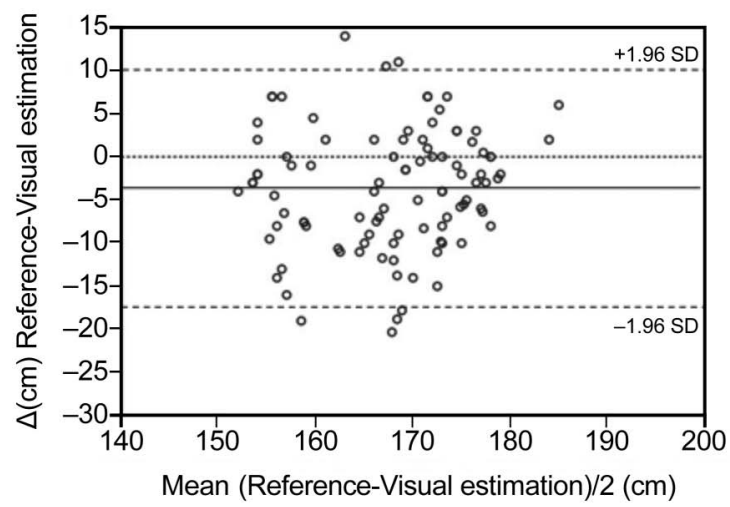

B

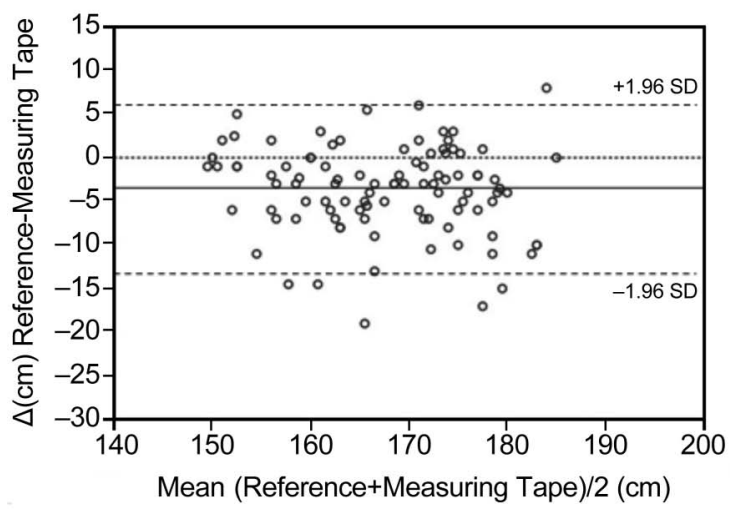

C

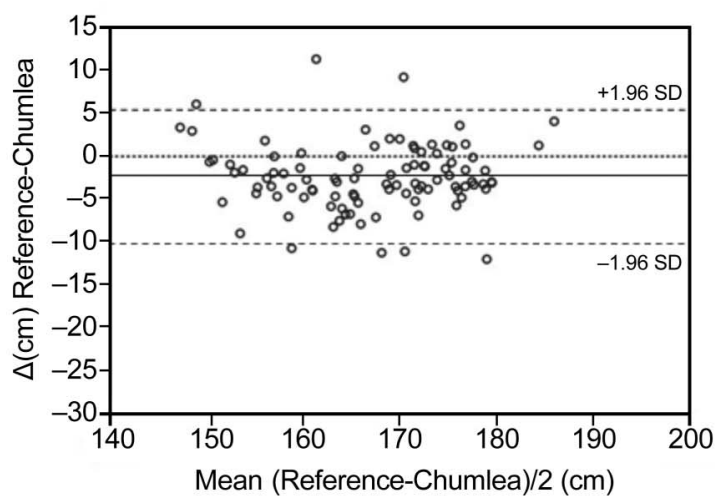

D

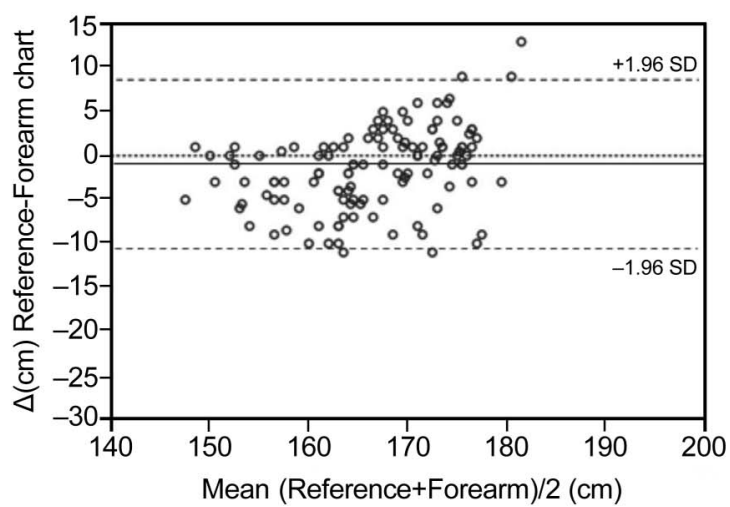

Fig. 3. Bland-Altman graph comparison of the reference value for height measurement and visual estimation (A), tape measurement (B), lower leg measurement (C), and forearm measurement (D). The solid lines represent the bias, and the dashed lines represent $95 \% \mathrm{Cl}$.

\section{Alternative Methods: Height Derived From Lower Leg (Chumlea Method) and Forearm Length}

Height derived from the lower leg and forearm correlated well with height gauge (Fig. 2). Compared with the reference, bias with the lower leg was $-2.4 \pm 3.9 \mathrm{~cm}$ (95\% CI -10.0 to 5.2 ), and bias with the forearm was $-1.3 \pm 5.0 \mathrm{~cm}(95 \% \mathrm{CI}-10.8$ to 8.6 ) (Fig. 3). Maximum errors with the lower leg and forearm methods were 11.9 and $20.0 \mathrm{~cm}$, respectively.

\section{Potential Impact on Protective Mechanical Ventilation}

The mean actual body weight was $30.3 \%$ higher than the PBW, and differences in the calculation of $\mathrm{V}_{\mathrm{T}}$ with actual body weight versus PBW were of similar amplitude. The errors for PBW were higher when the calculation of PBW was based on visually estimated heights and lower when the Chumlea method was used (Table 2). PBW errors of $>10 \%$ were present for $15 \%$ of the subjects when using the lower leg or forearm method, $25 \%$ when using a tape measure, and
$40 \%$ when relying on visual estimation (Table 2). As expected, the error in $\mathrm{V}_{\mathrm{T}}$ settings was marked when actual weight, rather than PBW, was used (Table 3). We compared the impact of the errors for shorter and taller subjects based on the median height of the subjects (ie, $167 \mathrm{~cm}$ ). The actual weight was higher than the PBW, from $+21 \%$ (in subjects $>167 \mathrm{~cm}$ ) to $+35 \%$ (in subjects $\leq 167 \mathrm{~cm}$ ) (Table 3). In comparison with the $\mathrm{V}_{\mathrm{T}}$ set with PBW, based on the reference height, maximal overestimation of $\mathrm{V}_{\mathrm{T}}$ settings in short subjects changed from $396 \mathrm{~mL}$ with an actual weight to 82 and $73 \mathrm{~mL}$ with the lower leg and forearm methods, respectively (See the supplementary materials at http://www.rcjour nal.com.). Among shorter subjects $(\leq 167 \mathrm{~cm})$, the proportion of women was $45.1 \%$ (23/51), whereas among taller subjects $(>167 \mathrm{~cm})$, the proportion of women was only $4.1 \%(2 / 49, P<.001)$ (Table 3$)$. Of those measuring less than the median height, $92 \%$ were women.

\section{Discussion}

Predicted rather than actual body weight should be used to determine the $\mathrm{V}_{\mathrm{T}}$ required for mechanically ventilated pa- 


\section{Measuring Height and Protective Ventilation}

Table 2. Differences in PBW Based on Reference Height and Other Measurement Methods

\begin{tabular}{|c|c|c|c|c|c|c|}
\hline & \multicolumn{5}{|c|}{ PBW Based on } & \multirow[b]{2}{*}{$P^{*}$} \\
\hline & $\begin{array}{l}\text { Height Gauge } \\
\text { (Reference) }\end{array}$ & $\begin{array}{c}\text { Visual } \\
\text { Estimation }\end{array}$ & $\begin{array}{c}\text { Tape } \\
\text { Measure }\end{array}$ & $\begin{array}{l}\text { Lower Leg } \\
\text { Measurement } \\
\text { (Chumlea) }\end{array}$ & $\begin{array}{c}\text { Forearm } \\
\text { Measurement }\end{array}$ & \\
\hline $\mathrm{PBW}$, mean $\pm \mathrm{SD}, \mathrm{kg}$ & $61.0 \pm 9.7$ & $64.6 \pm 8.8$ & $64.4 \pm 10.0$ & $63.2 \pm 9.7$ & $62.7 \pm 8.0$ & $<.001$ \\
\hline Bias, $\mathrm{kg}(95 \% \mathrm{CI})$ & & $-3.5(-15.8$ to 8.8$)$ & $-3.2(-12.2$ to 5.7$)$ & $-2.1(-9.1$ to 4.8$)$ & $-1.2(-10.1$ to 7.8$)$ & \\
\hline Error, mean $\pm \mathrm{SD}, \mathrm{kg}, \dagger$ & & $5.7 \pm 4.3$ & $4.2 \pm 3.6$ & $3.4 \pm 2.4$ & $3.5 \pm 3.1$ & $<.001$ \\
\hline Maximum error, $\mathrm{kg} \dagger$ & & 18.7 & 17.3 & 10.9 & 18.2 & \\
\hline Error, mean $\pm \mathrm{SD}, \% \dagger$ & & $10.0 \pm 8.5$ & $7.2 \pm 6.8$ & $5.8 \pm 4.3$ & $6.0 \pm 5.4$ & $<.001$ \\
\hline Subjects with error $>5 \%, n_{\dagger}^{\dagger}$ & & 63 & 48 & 41 & 45 & .005 \\
\hline Subjects with error $>10 \%, n \dagger$ & & 40 & 25 & 15 & 15 & $<.001$ \\
\hline Subjects with error $>20 \%, n \dagger$ & & 9 & 7 & 0 & 1 & .03 \\
\hline
\end{tabular}

Table 3. Impact of Height Measurement Method on $\mathrm{V}_{\mathrm{T}}$ Setting

\begin{tabular}{|c|c|c|}
\hline & $\begin{array}{l}\text { Subjects With Height }>167 \mathrm{~cm} \\
\qquad(n=49)^{*}\end{array}$ & $\begin{array}{l}\text { Subjects With Height }<167 \mathrm{~cm} \\
\qquad(n=51)^{*}\end{array}$ \\
\hline Female, $n(\%)$ & $2(4.1)$ & $23(45.0)$ \\
\hline Age, y & $63(57-68)$ & $71(63-75)$ \\
\hline BMI, $\mathrm{kg} / \mathrm{m}^{2}$ & $26.5(22.7-31.0)$ & $28.4(26.7-30.5)$ \\
\hline \multicolumn{3}{|l|}{ Height } \\
\hline Based on height gauge (reference) & $174(171-176)$ & $159(153-162)$ \\
\hline Based on lower leg & $175(172-178)$ & $163(157-167)$ \\
\hline Based on forearm & $173(170-175)$ & $163(158-166)$ \\
\hline Based on visual estimation & $175(170-178)$ & $165(159-171)$ \\
\hline Based on Tape measure & $176(173-180)$ & $162(158-168)$ \\
\hline \multicolumn{3}{|l|}{ Weight, $\mathrm{kg}$} \\
\hline Actual weight & $83.8(73.8-94.1)$ & $73.2(61.3-81.3)$ \\
\hline PBW based on height gauge (reference) & $69.2(66.4-71.5)$ & $54.2(47.2-58.7)$ \\
\hline PBW based on lower leg & $70.2(68.2-73.4)$ & $57.4(49.9-63.2)$ \\
\hline PBW based on forearm & $68.7(66.5-70.6)$ & $58.7(50.6-62.8)$ \\
\hline PBW based on visual estimation & $70.6(66.0-73.3)$ & $59.7(52.4-66.0)$ \\
\hline PBW based on tape measure & $71.5(68.7-75.1)$ & $57.0(52.4-62.4)$ \\
\hline \multicolumn{3}{|l|}{$\mathrm{V}_{\mathrm{T}}(8 \mathrm{~mL} / \mathrm{kg}), \mathrm{mL}$} \\
\hline Based on actual weight & $670(591-753)$ & $585(490-650)$ \\
\hline Based on height gauge (reference) & $554(531-572)$ & $434(377-470)$ \\
\hline Based on lower leg & $562(546-587)$ & $459(399-506)$ \\
\hline Based on forearm & $550(532-565)$ & $470(405-503)$ \\
\hline Based on visual estimation & $565(528-586)$ & $478(419-528)$ \\
\hline Based on tape measure & $572(550-601)$ & $456(419-499)$ \\
\hline \multicolumn{3}{|l|}{ Error in $\mathrm{V}_{\mathrm{T}}$ compared with reference, $\mathrm{mL} \dagger$} \\
\hline Based on actual weight & $-118(-192$ to -41$)$ & $-130(-202$ to -94$)$ \\
\hline Based on lower leg & $-12(-24$ to -9$)$ & $-27(-42$ to -12$)$ \\
\hline Based on forearm & $7(-5$ to 22$)$ & $-29(-51$ to -7$)$ \\
\hline Based on visual estimation & $-4(-33$ to 18$)$ & $-55(-80$ to -18$)$ \\
\hline Based on tape measure & $-18(-44$ to 4$)$ & $-22(-44$ to -7$)$ \\
\hline \multicolumn{3}{|c|}{$\begin{array}{l}* 167 \mathrm{~cm} \text { represents the median value for subjects' heights in this cohort. } \\
\dagger \text { The error was calculated for a target of } 8 \mathrm{~mL} / \mathrm{kg} \text { with the following formula: tidal volume }\left(\mathrm{V}_{\mathrm{T}}\right) \text { with height reference }-\mathrm{V}_{\mathrm{T}} \text { with other methods. Negative values correspond to overestimation of } \mathrm{V}_{\mathrm{T}} \text {. } \\
\text { BMI = body mass index } \\
\text { PBW = predicted body weight }\end{array}$} \\
\hline
\end{tabular}




\section{Measuring Height and Protective Ventilation}

tients. ${ }^{1,8,10}$ However, the patient's height is required to calculate PBW. ${ }^{1}$ We compared different direct and alternative methods to measure height in 100 bedridden mechanically ventilated subjects. We showed that significant differences exist between these methods (tape measure, visual estimation, and lower leg and forearm length) and the reference standard (gauge measurement). We found that visual estimation of height was an inaccurate method with large potential errors. The alternative methods, which were based on lower leg and forearm length, were close to the reference method and were at least as efficient as the tape measure method. This study represents the largest evaluation of different methods to assess height in bedridden subjects and demonstrates the potential impact on protective ventilation implementation.

Despite the paucity of data, several studies suggest that height is not being used to set the $\mathrm{V}_{\mathrm{T}}^{11,14}$ or that height is unknown because as many as $40 \%$ of ARDS patients had no height listed in their medical records, ${ }^{29}$ and consequently, visual estimation of height or weight is frequently being used. ${ }^{13,14,30}$ In surgical units, patients are frequently measured preoperatively. In a recent study, heights measured before surgery were available for 3,763 patients and were missing for only 6 patients $(0.16 \%) .{ }^{8}$ Although little data are available, it is likely that the tape measure method is also frequently used for medical bedridden patients when height is not known. In a survey of 20 ICUs in the United Kingdom, 15 measured patients with tape, and 5 estimated heights. ${ }^{13}$ Our results show that visual estimation and the tape measure method while subjects are supine are not accurate, with maximum errors being $\sim 20 \mathrm{~cm}$. These errors were associated with large errors in $\mathrm{V}_{\mathrm{T}}$ settings. Our results are in agreement with previous data that showed inaccuracy of visual estimations in different populations. ${ }^{15-18,31,32}$ To our knowledge, there is no study evaluating accuracy of the tape measure method in bedridden patients in comparison with the reference method with a height gauge when patients are standing upright.

Several methods have been described to obtain a patient's height indirectly, among which lower leg measurement (kneeheel length, Chumlea method), ${ }^{24-26}$ forearm measurement (from elbow to wrist), and demispan (distance from the middle of the sternal notch to the tip of the middle finger in the coronal plane) are the most frequently evaluated. ${ }^{27,33}$ These alternative methods are potentially useful for bedridden patients or mobility-impaired patients. ${ }^{24}$ For these patients, the tape measure method may be difficult to use (the subject's position in bed or the use of a short tape measure is a potential source of error) and may not be accurate, as we describe in this study. The use of a flexible tape measure to measure the lower leg is a potentially interesting solution. ${ }^{34}$

The Chumlea method, which allows height estimation based on knee-heel length, has been validated in large cohorts. ${ }^{24-26,35}$ In elderly patients, who represent the majority of mechani- cally ventilated subjects, this method was accurate in determining height. ${ }^{25,26}$ Our study evaluated 2 indirect methods (based on lower leg and forearm measurements), and we showed that these methods were well correlated with the reference method and were at least as accurate in bedridden subjects as using tape measure. Maximum errors were equivalent (with forearm measurement) or lower (with lower leg measurement) in comparison with a tape measure.

\section{Potential Impact on Implementation of Protective Ventilation}

In this study, $\mathrm{V}_{\mathrm{T}}$ was much higher when actual body weight rather than PBW was considered, which is in line with previous reports. ${ }^{11}$ It is now recommended to set $\mathrm{V}_{\mathrm{T}}$ based on PBW rather than actual body weight. 1,8,10 However, errors in the measurement or estimate of a patient's height are responsible for errors when calculating PBW and, consequently, $\mathrm{V}_{\mathrm{T}}$ settings. It is likely that visual estimation is frequently used in mechanically ventilated patients. In the present study, the error in height estimation was greater in short subjects. Importantly, in this subgroup of shorter subjects, almost all were women. Consequently, the impact on $\mathrm{V}_{\mathrm{T}}$ setting was greater in this subgroup. Patients of shorter height were less likely to receive protective ventilation in previous studies. ${ }^{36,37}$

The tape measure method was also associated with potentially high errors in $\mathrm{V}_{\mathrm{T}}$ settings. Overestimation of $\mathrm{V}_{\mathrm{T}}$ reached almost $150 \mathrm{~mL}$ when the tape measure method was used to calculate PBW rather than the reference height. With alternative methods (lower leg and forearm measurements), maximum errors in $\mathrm{V}_{\mathrm{T}}$ were limited to between 73 and $87 \mathrm{~mL}$. In addition, because of the formula for the PBW calculation, an error in height measurement or estimation leads to higher errors in $\mathrm{V}_{\mathrm{T}}$ settings in women compared with men. (See the supplementary materials at http://www.rcjournal.com.) Our data help explain, in part, why women frequently receive higher $\mathrm{V}_{\mathrm{T}}$ compared with men.7,8,11,12,30,36

These data highlight the importance of height in effectively reducing $\mathrm{V}_{\mathrm{T}}$, which may be difficult when accurate height measurements are not available. Consequently, finding an accurate and easy method to obtain height measurements in bedridden patients is of great importance.

\section{Limitations}

Our study has several limitations. The Chumlea method (based on lower leg measurement) was not recorded directly in bedridden subjects, but preoperatively in seated subjects with knees bent at a $90^{\circ}$ angle, which limits the chance of errors. The results may therefore not be directly transposable to the situation of mechanically ventilated supine subjects. The present study is to be considered as a first step in assessing this method as a potential alternative 


\section{Measuring Height and Protective Ventilation}

method of measurement. In a subsequent study, we evaluated a modified Chumlea method using lower leg measurement in bedridden subjects. Preliminary evaluation of this new method showed promising results, with very close correlation with the reference method. ${ }^{38}$ In the present study, we did not test the reproducibility of the measurements with different investigators, and this will need to be performed in subsequent studies.

One must remember that the Chumlea stature prediction equations have been made specifically for defined populations ${ }^{25}$ and that specific equations have been developed and should be used for differing populations. ${ }^{39,40}$

$\mathrm{V}_{\mathrm{T}}$ may not be the optimum value to consider in mechanically ventilated patients. Indeed, some authors advocate the use of other physiologic surrogates, such as transpulmonary pressure or lung volumes, instead of $\mathrm{V}_{\mathrm{T}}$ per PBW, given the variable effect of a unique value of $V_{T}$ in a large population of subjects. ${ }^{41}$

\section{Clinical Relevance}

Protective mechanical ventilation is insufficiently implemented ${ }^{19-23}$ due to several identified barriers; it is likely that difficulty in accurately measuring a subject's height and the lack of availability of derived formulas to calculate PBW are additional barriers. We described in this study several potential indirect methods that are at least as accurate as the tape measure method in bedridden subjects and that are more achievable. The data presented here also point out the inaccuracy of the visual estimation method, which can lead to large errors in $V_{T}$ settings. Visual estimation of height should definitively be avoided, as well as the use of actual body weight to determine $\mathrm{V}_{\mathrm{T}}{ }^{10}$

The optimum $\mathrm{V}_{\mathrm{T}}$ to prevent ${ }^{5,42}$ or treat ${ }^{4}$ ARDS in mechanically ventilated patients is still not clearly defined. It is well accepted, however, that high $\mathrm{V}_{\mathrm{T}}$ increases mortality in ARDS patients ${ }^{1,4}$ and is associated with poor outcome in patients without ARDS.5,6 To this end, implementation of low $\mathrm{V}_{\mathrm{T}}$ strategies requires patients' heights to calculate PBW and to choose $\mathrm{V}_{\mathrm{T}}$ based on PBW rather than on actual body weight. The formulas used in the present study have been implemented in a free smartphone application (iAnthropometer ICU) that may facilitate implementation of protective ventilation. ${ }^{43}$

Use of reliable methods to measure height is also desirable to homogenize practices in the clinical field and for research purposes. In a meta-analysis, Eichacker et $\mathrm{al}^{4}$ showed that among the 5 randomized controlled trials evaluating different $\mathrm{V}_{\mathrm{T}}$ values in ARDS subjects, 4 different methods were used to determine weight: actual weight, dry weight, ideal body weight, and PBW. These various surrogates of weight were acceptable when the rates of obesity (body mass index $>30 \mathrm{~kg} / \mathrm{m}^{2}$ ) were $\sim 10 \%$, but today, these rates now approach nearly $40 \%$ in many countries, ${ }^{44}$ and consequently, actual body weight cannot be used to set the ventilator because of the risk of delivering high $\mathrm{V}_{\mathrm{T}} \cdot{ }^{8} \mathrm{In}$ daily practice, the alternative methods that we describe may be more accurate than visual estimation and easier to apply in comparison with the tape measure method.

\section{Conclusions}

We showed that the method used to obtain a patient's height during mechanical ventilation might not be accurate and may have an impact on $\mathrm{V}_{\mathrm{T}}$ settings. $\mathrm{A} \mathrm{V}_{\mathrm{T}}$ set according to actual body weight leads to large errors and should not be used; PBW requiring the patient's height should be used instead. The use of height measured with a tape measure, as well as visual estimation of height, can also lead to large errors in $\mathrm{V}_{\mathrm{T}}$ settings. When reference height is not available in patients undergoing mechanical ventilation, alternative methods to obtain patients' heights based on lower leg and forearm measurements could be useful to facilitate the application of protective mechanical ventilation to prevent ${ }^{5}$ or treat ${ }^{1,2}$ ARDS. Knowledge and accurate application of a subject's height are low-cost therapeutic interventions based on basic physiology, as lung size is closely related to height. ${ }^{9}$ This simple yet under-recognized fact should not be overlooked, especially if one considers that the only proven treatment of ARDS relies on the application of appropriate ventilatory settings. ${ }^{1,2}$

\section{ACKNOWLEDGMENT}

We thank Dr Jed Lipes for manuscript revisions and English editing.

\section{REFERENCES}

1. Ventilation with lower tidal volumes as compared with traditional tidal volumes for acute lung injury and the acute respiratory distress syndrome. The Acute Respiratory Distress Syndrome Network. N Engl J Med 2000;342(18):1301-1308.

2. Girard TD, Bernard GR. Mechanical ventilation in ARDS: a stateof-the-art review. Chest 2007;131(3):921-929.

3. Putensen C, Theuerkauf N, Zinserling J, Wrigge H, Pelosi P. Metaanalysis: ventilation strategies and outcomes of the acute respiratory distress syndrome and acute lung injury. Ann Intern Med 2009;151(8): 566-576.

4. Eichacker PQ, Gerstenberger EP, Banks SM, Cui X, Natanson C. Meta-analysis of acute lung injury and acute respiratory distress syndrome trials testing low tidal volumes. Am J Respir Crit Care Med 2002;166(11):1510-1514.

5. Lellouche F, Lipes J. Prophylactic protective ventilation: lower tidal volumes for all critically ill patients? Intensive Care Med 2013;39(1): 6-15.

6. Serpa Neto A, Cardoso SO, Manetta JA, Pereira VG, Espósito DC, Pasqualucci Mde O, et al. Association between use of lung-protective ventilation with lower tidal volumes and clinical outcomes among patients without acute respiratory distress syndrome: a meta-analysis. JAMA 2012;308(16):1651-1659.

7. Gajic O, Dara SI, Mendez JL, Adesanya AO, Festic E, Caples SM, et al. Ventilator-associated lung injury in patients without acute lung injury at the onset of mechanical ventilation. Crit Care Med 2004; 32(9):1817-1824.

8. Lellouche F, Dionne S, Simard S, Bussières J, Dagenais F. High tidal volumes in mechanically ventilated patients increase organ dysfunction after cardiac surgery. Anesthesiology 2012;116(5):1072-1082. 


\section{Measuring Height and Protective Ventilation}

9. Hepper NG, Fowler WS, Helmholz HF Jr. Relationship of height to lung volume in healthy men. Dis Chest 1960;37:314-320.

10. Pelosi $\mathrm{P}$, de Abreu MG. Tidal volumes during general anesthesia: size does matter! Anesthesiology 2012;116(5):985-986.

11. Kam EP, Eslick GD, James A, Benson JP. Acute respiratory distress syndrome (ARDS) and low tidal volume ventilation: the debate about weight. Intensive Care Med 2004;30(7):1502.

12. Jaber S, Coisel Y, Chanques G, Futier E, Constantin JM, Michelet P, et al. A multicentre observational study of intra-operative ventilatory management during general anaesthesia: tidal volumes and relation to body weight. Anaesthesia 2012;67(9):999-1008.

13. Leary TS, Milner QJ, Niblett DJ. The accuracy of the estimation of body weight and heig ht in the intensive care unit. Eur J Anaesthesiol 2000;17(11):698-703

14. Tallach R, Jefferson P, Ball DR. Mechanical ventilation for patients with ARDS: a UK survey on calculation of tidal volume. Intensive Care Med 2006;32(1):176.

15. Bloomfield R, Steel E, MacLennan G, Noble DW. Accuracy of weight and height estimation in an intensive care unit: implications for clinical practice and research. Crit Care Med 2006;34(8):2153-2157.

16. Hendershot KM, Robinson L, Roland J, Vaziri K, Rizzo AG, Fakhry SM. Estimated height, weight, and body mass index: implications for research and patient safety. J Am Coll Surg 2006;203(6):887-893.

17. Maskin LP, Attie S, Setten M, Rodriguez PO, Bonelli I, Stryjewski ME, Valentini R. Accuracy of weight and height estimation in an intensive care unit. Anaesth Intensive Care 2010;38(5):930-934.

18. Determann RM, Wolthuis EK, Spronk PE, Kuiper MA, Korevaar JC, Vroom MB, Schultz MJ. Reliability of height and weight estimates in patients acutely admitted to intensive care units. Crit Care Nurse 2007;27(5):48-55

19. Umoh NJ, Fan E, Mendez-Tellez PA, Sevransky JE, Dennison CR, Shanholtz C, et al. Patient and intensive care unit organizational factors associated with low tidal volume ventilation in acute lung injury. Crit Care Med 2008;36(5):1463-1468.

20. Weinert CR, Gross CR, Marinelli WA. Impact of randomized trial results on acute lung injury ventilator therapy in teaching hospitals. Am J Respir Crit Care Med 2003;167(10):1304-1309.

21. Young MP, Manning HL, Wilson DL, Mette SA, Riker RR, Leiter JC, et al. Ventilation of patients with acute lung injury and acute respiratory distress syndrome: has new evidence changed clinical practice? Crit Care Med 2004;32(6):1260-1265.

22. Scales DC, Adhikari NK. Lost in (knowledge) translation: "All breakthrough, no follow through"? Crit Care Med 2008;36(5):1654-1655.

23. Villar J, Kacmarek RM, Hedenstierna G. From ventilator-induced lung injury to physician-induced lung injury: why the reluctance to use small tidal volumes? Acta Anaesthesiol Scand 2004;48(3):267-271.

24. Chumlea WC, Guo SS, Steinbaugh ML. Prediction of stature from knee height for black and white adults and children with application to mobility-impaired or handicapped persons. J Am Diet Assoc 1994; 94(12):1385-1388, 1391.

25. Chumlea WC, Guo SS, Wholihan K, Cockram D, Kuczmarski RJ, Johnson CL. Stature prediction equations for elderly non-Hispanic white, non-Hispanic black, and Mexican-American persons developed from NHANES III data. J Am Diet Assoc 1998;98(2):137-142.
26. Chumlea WC, Roche AF, Steinbaugh ML. Estimating stature from knee height for persons 60 to 90 years of age. J Am Geriatr Soc 1985;33(2):116-120.

27. Malnutrition Advisory Group BAPEN. Malnutrition Universal Screening Tool. http://www.bapen.org.uk/pdfs/must/must_full.pdf. Accessed May 14, 2014.

28. Bland JM, Altman DG. Statistical methods for assessing agreement between two methods of clinical measurement. Lancet 1986;1(8476): 307-310.

29. Jia X, Malhotra A, Saeed M, Mark RG, Talmor D. Risk factors for ARDS in patients receiving mechanical ventilation for $>48 \mathrm{~h}$. Chest 2008;133(4):853-861.

30. Diacon AH, Koegelenberg CF, Klüsmann KJ, Bolliger CT. Challenges in the estimation of tidal volume settings in critical care units. Intensive Care Med 2006;32(10):1670-1671.

31. Coe TR, Halkes M, Houghton K, Jefferson D. The accuracy of visual estimation of weight and height in pre-operative supine patients. Anaesthesia 1999;54(6):582-586.

32. Uesugi T, Okada N, Sakai K, Nishina K, Mikawa K, Shiga M. Accuracy of visual estimation of body height and weight in supine paediatric patients. Paediatr Anaesth 2002;12(6):489-494.

33. Mitchell CO, Lipschitz DA. Arm length measurement as an alternative to height in nutritional assessment of the elderly. JPEN J Parenter Enteral Nutr 1982;6(3):226-229.

34. Rogerson R, Gallagher ML, Beebe A. Flexible tape is an appropriate tool for knee height measurement and stature estimation of adults with developmental disabilities. J Am Diet Assoc 2000;100(1):105-107.

35. Chumlea WC, Guo S. Equations for predicting stature in white and black elderly individuals. J Gerontol 1992;47(6):M197-M203.

36. Han S, Martin GS, Maloney JP, Shanholtz C, Barnes KC, Murray S, Sevransky JE. Short women with severe sepsis-related acute lung injury receive lung protective ventilation less frequently: an observational cohort study. Crit Care 2011;15(6):R262.

37. Walkey AJ, Wiener RS. Risk factors for underuse of lung-protective ventilation in acute lung injury. J Crit Care 2012;27(3):323.e1-323.e9.

38. Bojmehrani A, Bouchard PA, Bouchard C, L'Her E, Lellouche F. Evaluation of new tool to measure patient's height during mechanical ventilation: impact on protective ventilation implementation. Am J Respir Crit Care Med 2012;185:A1720.

39. Hwang IC, Kim KK, Kang HC, Kang DR. Validity of stature-predicted equations using knee height for elderly and mobility impaired persons in Koreans. Epidemiol Health 2009;31:e2009004.

40. Shahar S, Pooy NS. Predictive equations for estimation of stature in Malaysian elderly people. Asia Pac J Clin Nutr 2003;12(1):80-84.

41. Gattinoni L. Counterpoint: is low tidal volume mechanical ventilation preferred for all patients on ventilation? No. Chest 2011;140(1): 11-13; discussion 14-15.

42. Schultz MJ, Haitsma JJ, Slutsky AS, Gajic O. What tidal volumes should be used in patients without acute lung injury? Anesthesiology 2007;106(6):1226-1231.

43. L'Her E, Lellouche F, Stindel E, Zemirline A. iAnthropometer ICU1. http://itunes.apple.com/ca/app/ianthropometer-icu-1/id428778012? $\mathrm{mt}=8$. Accessed May 12, 2014.

44. Prentice AM. The emerging epidemic of obesity in developing countries. Int J Epidemiol 2006;35(1):93-99.

This article is approved for Continuing Respiratory Care Education credit. For information and to obtain your CRCE

(free to AARC members) visit www.rcjournal.com

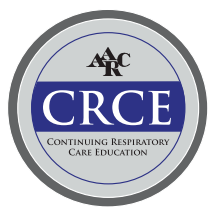

